\title{
La metodología de la investigación $y$ los límites del conocimiento humano
}

FELIPE MARTINNEZ RIZO

Departamento de Educación/UAA

I. NTRODUCCIÓN

En los ambientes relacionados con la investigación educativa, y con la investigación en ciencias del hombre en general, se habla mucho en la actualidad de una polémica que enfrenta a los partidarios de enfoques diferentes de hacer investigación agrupados, en forma bastante simplista, en dos bandos de desigual tamaño y coherencia, a los que se suele designar con las también simplificadoras etiquetas de cuantitativistas y cualitativistas.

Por poco que se ahonde en el análisis de esta cuestión, se pueden encontrar con facilidad varios puntos en los que se aprecia que las cosas son más complejas de lo que parecen:

- por una parte, no hay únicamente dos bandos, sino que en realidad hay toda una gama de posturas y corrientes metodológicas que no pueden reducirse a una pareja opuesta, sino que contienen toda una gama de matices en diferentes dimensiones de la cuestión;

- por otra, lejos de ser algo reciente, propio de nuestra época, la discusión metodológica tiene raíces muy hondas, pudiendo encontrarse antecedentes precisos de la polémica actual en los años 50s y 60 s, pero también en los 30 s y 20 s de nuestro siglo, en la primera década de éste y las últimas del pasado, a principios del XIX, a 
finales del xvIII, y hasta a mediados del XVII ( $c f r$. Martínez Rizo F., 1991);

- y por último, es claro que la dicotomía que, por razones de brevedad, en lo sucesivo designaré con la expresión "cuanti-cuali", no corresponde a la complejidad de la cuestión, que no se reduce a la dimensión de la cuantificación, sino que incluye otros muchos aspectos.

En este trabajo sostendré la tesis de que una diferencia fundamental entre los enfoques de investigación mencionados es la concepción del conocimiento que suponen. A riesgo de incurrir, a mi vez, en una sobresimplificación del punto, distingo dos maneras de concebir el conocimiento: una analítica y otra sintética.

Sin dejar de reconocer algún mérito a la segunda, argumentaré a favor de la primera, o sea de la forma analítica, como el tipo de acercamiento que inevitablemente tenemos que usar los humanos para tratar de abordar la realidad. De esta premisa se derivarán importantes consecuencias en cuanto a la polémica cuanti-cuali.

\section{LA LÓGICA DIALÉCTICA VS. LA LÓGICA FORMAL}

Es conocido el hecho de que, al terminar la Segunda Guerra Mundial, y por circunstancias históricas que pueden describirse con precisión, algunas corrientes particulares de diversas ciencias del hombre, como el conductismo en psicología y el funcionalismo en sociología, llegaron a adquirir tal supremacía en sus ámbitos respectivos que se puede afirmar que se acercaron a la situación de "paradigmas" en el sentido original que Thomas S. Kuhn daba a este vocablo.

En forma concomitante, adquirió gran relevancia un estilo de hacer investigación que luego fue caracterizado con la etiqueta de positivista.

Las críticas a este tipo de investigación, que han proliferado desde los años 60s hasta hoy, han sido muchas y diversas, pero pro- 
bablemente las más radicales fueron las que llegaron a rechazar la misma lógica formal, por considerarla la base de las limitaciones de la investigación llamada positivista, contraponiéndole la llamada lógica dialéctica.

Aunque su expresión inicial tuvo lugar durante el estalinismo, todavía en un momento tan tardío como 1978, y en los Estados Unidos, se reimprimió una obra de 1942 con estas frases:

...Afirmamos que la lógica formal era el pensamiento dominado por las leyes de identidad, de contradicción y del tercero excluído... que constituyen las normas imperantes de pensamiento en el mundo burgués... La lógica formal precedió a la dialéctica en la evolución histórica de la lógica, como ocurre habitualmente en el desarrollo intelectual de los individuos. Luego, los dialécticos se elevaron por encima de la crítica de la lógica formal, la derrocaron y sustituyeron como su contrario revolucionario, su sucesor y superior...

...Podemos destacar cinco errores básicos, o elementos de ficción, inherentes a las leyes de la logica formal:

- exige un universo estático

- levanta barreras infranqueables entre las cosas

- excluye la diferencia de la identidad

- sus leyes son presentadas como absolutas

- puede explicar presumiblemente todo, excepto a sí misma... (1979, pp. 3558).

Y todavía en 1969, aunque con muchos matices con respecto a la primera versión de su trabajo, fechada en 1946, el importante pensador marxista francés Henri Lefevre afirmaba:

...haber probado, en las páginas anteriores, la posibilidad y la necesidad de una lógica concreta, que envuelva y supere a la lógica formal... (1976: 219)

Y luego resumía las leyes del método dialéctico como sigue:

- ley de la interacción universal... nada existe aisladamente...

- ley del movimiento universal...

- ley de la unidad de los contradictorios...

- transformación de cantidad en calidad...

- ley del desarrollo en espiral (de la superación)... (1976: 275-278). 
Lo trasnochado de estas opiniones, que ya casi nadie sostiene, era ridiculizado hace ya 20 años por Alfredo Deaño, en la introducción a la primera edición de su excelente Introducción a la lógica formal, en los siguientes términos:

...Y dos son, en España en 1973, los enemigos fundamentales de la lógica formal: los que, para abreviar, llamaremos "dialécticos", y aquellos otros a los que, en un sentido que luego explicaremos, vamos a denominar "medievales".

A los primeros debemos algunas de las manifestaciones más irritantes y a la vez regocijantes acerca de la ciencia que con este libro empezamos a exponer. Han dado en pensar que la lógica formal es una especie de Derecho Mercantil del intelecto: así como éste no sería otra cosa que la regulación jurídica de determinados procesos económicos que tienen lugar en la sociedad capitalista y que desaperecerán con ésta, así también la lógica constituiría la regulación formal de los procesos de pensamiento que se desarrollan en las mentes positivistas. La lógica formal -logica del pensamiento administrado- ha de ser, como el capitalismo, superada.

Es imposible ocuparse aquí en detalle de analizar esta idea, si es que de una idea se trata. Una de dos: 0 es que hay que postular la extravagante hipótesis de que son dos los tipos de cerebro humano -cerebros encadenados, con conexiones neuronales "de carril", de cuyo autorrepresivo comportamiento daría perfecta cuenta la lógica formal, y (fase superior de la evolución) cerebros libres, de neurona ágil, cerebros bravos capaces de desconcertantes conexiones, cerebros, en suma, "dialécticos" entre comillas... (1976: vol. I, pp. 11-12).

Con un poco más detalle que Deaño, y por ser de especial interés para el tema de este trabajo, me ocuparé con algún detenimiento de la primera de las leyes enlistadas por Lefevre, la que él llama de la interacción universal.

Coincidiendo en este punto con las corrientes llamadas interpretativas o hermenéuticas, el pensamiento dialéctico, en su versión marxista, insistió siempre en que una característica que lo distinguía del pensamiento positivista radicaba, precisamente, en su carácter totalizador u holístico, que incluía la dimensión dinámica de la realidad social, la historia. 
Cuando se criticaba una investigación llamada positivista por no incluir lo relativo a la lucha de clases al abordar alguna cuestión, se decía: al dejar fuera ese aspecto, la investigación se invalida, ya que en la realidad todo está relacionado con todo (la interacción universal de Lefevre), por lo que un análisis parcializador es falso.

No era raro ver comenzar cualquier trabajo marxista con una especie de muletilla que rezaba, poco más o menos, así: "en este trabajo adoptamos el punto de vista de que la realidad constituye una totalidad social e históricamente determinada..."

Como puede verse, el punto central de la contraposición hecha por los dialécticos entre su manera de abordar una investigación y la de los no dialécticos, no radicaba en la cuantificación, sino en la cuestión del enfoque totalizador u holístico en contraposición al acercamiento parcializador 0 analítico.

Es fácil mostrar que siempre se dejan innumerables aspectos fuera del marco de la atención del investigador, por lo que toda investigación es parcializadora. Además de los intereses de clase, o de la ideología respectiva, ¿por qué no incluir, por ejemplo, el signo zodiacal de las personas, o su tipo sanguíneo?

Pronto llegará el dialéctico a un dilema sin escapatoria: o bien se acepta literalmente la exigencia de incluir en la investigación todo, lo cual es estrictamente imposible, o bien se modifica el concepto de totalidad, y pasa a hablarse de totalidad construida, o sea un conjunto de elementos relevantes para la explicación del fenómeno de que se trate.

En el segundo caso, puede discutirse obviamente sobre la mayor o menor pertinencia de la clase social o del signo zodiacal como elemento explicativo potencialmente relevante, y podrá haber partidarios de uno u otro elemento. Pero se habrá dado un paso enorme, al abandonar definitivamente la pretensión de acercamiento totalizador en sentido estricto.

Con lo que se dirá más abajo, tal vez haya lugar a afirmar, en forma análoga a lo que sostenían los dialécticos de la era stalinia- 
na, que la pretensión de abordar la totalidad indiferenciadamente es característica de una etapa anterior a la del dominio de las operaciones formales piagetianas, puesto que el manejo de tipologías multidimensionales requiere del manejo de las combinatorias, propio de la etapa del pensamiento formal.

\section{LA PARTE DE RAZÓN DE LA DIALÉCTICA}

En la actualidad, especialmente después del derrumbe del llamado socialismo real, el marxismo está tan desprestigiado que ya apenas queda quien recuerde las aberraciones que atacaba Deaño hace 20 años.

Pero, como sucede siempre, había un cierto fundamento en esos errores, que tan sencillo resultaba refutar con unas cuantas distinciones elementales.

Ese fundamento lo expresa con gran claridad el biólogo e historiador de la ciencia Stephen Jay Gould, al estudiar las concepciones cíclicas y lineales del tiempo:

...Por razones que no alcanzo a comprender, a la mente humana le encanta dicotomizar, por lo menos en nuestra cultura, pero más probablemente no sólo en ella, como han demostrado los análisis estructuralistas de los sistemas de pensamiento no occidentales. Es posible extender nuestra propia tradición por lo menos hasta el famoso aforismo de Diógenes Laercio: 'Protágoras afirmó que siempre hay dos lados en cada cuestión, exactamente opuestos el uno al otro' (1987: 8).

...Frecuentemente tratamos de encerrar a nuestro complejo mundo dentro de los confines de lo que puede abarcàr la razón humana, reduciendo el hiperespacio de la verdadera complejidad conceptual a una sola línea, y luego etiquetando los extremos de esa línea con nombres construidos como polarmente contrapuestos, de manera que toda la riqueza de la realidad se reduce a una sola dimensión, al contraste de dos imaginarios opuestos. Todas estas dicotomías son falsas (o incompletas), porque sólo pueden capturar una fracción de la diversidad real, pero unas pueden ser mejores (o por lo menos más productivas) que otras, porque el eje limitado de su contraste particular puede expresar algo más fundamental, con implicaciones más amplias, o que 
esté más en consonancia con las preocupaciones de quienes discuten... (1987: 191).

En efecto: en oriente y occidente, como ha mostrado Lévi- Strauss, tendemos a captar el mundo en dicotomías simples: arriba-abajo, adelante-atrás, humano-no humano, naturaleza-cultura, crudo-cocido, bueno-malo, verdadero-falso, masculino-femenino, etc., etc.

Las primeras investigaciones que pretendieron utilizar instrumentos rigurosos para captar la realidad humana y social con mayor precisión que el sentido común, se dieron a la tarea de construir instrumentos de medición, cuestionarios y escalas de actitud, entrevistas y guías de observación estructuradas, etc., pero tuvieron que hacer esto en una época en la que los conceptos y las técnicas del análisis multivariado apenas se estaban desarrollando, y sin la ayuda de las modernas computadoras personales para poder manejar los enormes volúmenes de datos y operaciones que tales técnicas implican.

Por lo anterior no resulta sorprendente que las construcciones conceptuales subyacentes a dichas investigaciones sean, muchas veces, bastante elementales, y que caigan precisamente en esa reducción de la complejidad de lo real a unas 'cuantas dimensiones, y que éstas se manejen, simplificadamente a su vez, en forma dicotómica.

Y tanto los dialécticos de los 40s y 50s, como los interpretativos y hermenéuticos de los 60s en adelante, reaccionaron ante estas simplificaciones, pero la reacción no parece haber dado en el clavo.

Los dialécticos culparon a la lógica formal, y cayeron en las aberraciones ya citadas, sin ver que sus propios planteamientos -capitalismo vs. socialismo, burguesía vs. proletariado- eran excelentes ejemplos de concepciones paupérrimas, unidimensionales y dicotómicas.

Y tanto ellos como los hermenéuticos buscaron el imposible de un acercamiento totalizador. 
Stephen Jay Gould apunta en otra dirección, que parece más adecuada, para superar las limitaciones de las dicotomías simples:

...Yo solía enojarme mucho contra tales simplificaciones, pero ahora pienso que puede ser más productivo proponer otra estrategia para alcanzar una visión más rica y plural. No creo poder convencer a la gente de que deje de utilizar la familiar y reconfortante táctica de elaborar dicotomías. Pero tal vez, en lugar de ello, podamos ampliar el marco de referencia de las discusiones buscando otras dicotomías mas apropiadas, o simplemente distintas, de las convencionales. Todas las dicotomías son simplificaciones, pero el organizar un debate a lo largo de varios ejes, de varias dimensiones dicotómicas que se crucen ortogonalmente, puede ofrecer la amplitud de un espacio intelectual propiamente dicho, sin forzarnos a abandonar una de nuestras herramientas intelectuales más reconfortantes. (1987: 9).

Una tipología no es sino el resultado de combinar varias dimensiones, cada una de las cuales puede tener dos o más valores, que al cruzarse nos dan una combinatoria cuya complejidad aumenta rápidamente.

Así, el caso más sencillo de dos dimensiones dicotómicas nos da ya cuatro tipos ideales, $2 \times 2$. Y una tipología con el nada descomunal número de cinco dimensiones, que tengan respectivamente $2,3,4,5$ y 6 valores, nos daría ya un producto de 720 tipos.

La transformación que representa el paso de una situación unidimensional a una de varias, aunque sean pocas, dimensiones combinables entre sí (ortogonales, en la precisa terminología de Gould) puede apreciarse en el título de un artículo reciente de sociología de la educación.

Al tratar de dar cuenta de las posiciones actuales en cuanto al tema preciso de la desigualdad social y educativa, J. C. Jacob considera que hay que superar las tradicionales concepciones dicotómicas (sociología funcionalista vs. sociología crítica), para buscar una clasificación algo más compleja, que tenga en cuenta los matices de las posturas reales de los numerosos investigadores que se han ocupado del tema. Jacob titula su artículo: "Teorías de la desigualdad social y educativa: de la dicotomía a una tipología" (1981). 


\section{El CONOCIMIENTO DE LO SINGULAR EN LA ESCOLÁSTICA}

Para tratar de ver más claro este complejo asunto, lo abordaré ahora desde un punto de vista poco usual, pero que resulta esclarecedor: desde las reflexiones de la filosofía escolástica, en la estela de Aristóteles, sobre el conocimiento humano.

En su clásico estudio sobre la metafísica occidental, Heimsoeth nos recuerda que es apenas con Fichte cuando el pensamiento filosófico llega a determinar "de un modo claro e inequívoco la relación de lo individual con el conjunto, con la armonía de los seres" (1960: 272). La concepción moderna del individuo, aparentemente tan fundamental en el pensamiento occidental es, pues, bastante reciente. Todavía el contemporáneo y crítico de Fichte, Friedrich Heinrich Jacobi afirma que "los conceptos del entendimiento fracasan siempre frente a lo individual. Un individuo perfectamente comprendido es tan inconcebible como un hierro de madera" (Heimsoeth, 1960: 269).

Esta prioridad de lo general con respecto a lo particular, no sólo en el nivel cognoscitivo, sino precisamente en el ontológico, esta "subordinación metafísica de lo individual a lo general" es "otro rasgo sumamente característico de la imagen del universo en la filosofía antigua..." (Heimsoeth, 1960: 239).

El caso prototípico es el de Platón, para quien la realidad fundamental no era la de los seres concretos, individuales, sino la del mundo de las ideas, de los seres abstractos, generales, ideales.

Con Aristóteles, y durante los dos mil años siguientes, si la prioridad ontológica de lo universal fue una cuestión debatida, la prioridad cognoscitiva fue algo comúnmente aceptado.

Precisemos inmediatamente que se trata de prioridad cognoscitiva en el nivel intelectual, no en el meramente sensitivo. Todo mundo estaba de acuerdo en que la sensibilidad nos proporciona información sobre los seres concretos, particulares o individuales que nos rodean. Pero para que las sensaciones se transformen en 
conocimientos intelectuales, en ideas, es necesario un tipo de procesamiento, de abstracción, que llevó a todos los filósofos al planteamiento, que hoy suena raro, de la prioridad gnoselógica o epistemológica de lo universal.

El problema clásico llamado "de los universales" surge precisamente de esa aparente paradoja: por una parte, pocas dudas pueden caber de que los seres que existen y que percibimos son singulares, "individuos" en el sentido original del término ( $c f r$. Ferrater Mora, 1980, vol 2: 1667-1671). Pero, por otra parte, las palabras con que los designamos tienen como característica su generalidad: piedra, perro o lanza son nombres o sustantivos comunes. Y al comenzar a hablar, los niños lo hacen utilizando términos muy generales, como cosa 0 algo, o dando a nombres más precisos un sentido más amplio, que sólo después.se va particularizando. Ya Aristóteles decía que, en cuanto al conocimiento, "debemos avanzar de lo general a lo particular", y hacía notar que "un niño comienza llamando 'papá' a todos los hombres, y 'mamá' a todas las mujeres, y más tarde distingue a unas personas de otras" (Física, libro I, I).

Santo Tomás dedica la Cuestión 86 de la Summa Theologica al tema de "qué es lo que conoce nuestro entendimiento en las cosas materiales", y le dedica cuatro artículos, en el primero de los cuales se pregunta, precisamente, "Si nuestro entendimiento conoce lo singular". Para introducir su respuesta, aduciendo como siempre un argumento de autoridad contrario a las opiniones falsas que después refutará, cita a Aristóteles, quien en la Física afirma que "el universal es conocido por la razón, y el singular es conocido por el sentido". Y en su respondeo dicendum quod el Aquinatense precisa que:

...Nuestro entendimiento no puede conocer lo singular en las cosas materiales directa y primariamente. La razón es que el principio de individuación en las cosas materiales es la materia, mientras que nuestro entendimiento, como hemos dicho, entiende abstrayendo la especie inteligible de tal materia. Pero lo que se abstrae de la materia individual es lo universal. Por lo tanto nuestro intelecto conoce directamente solamente lo universal (Q. 86, Art. I). 
En la cuestión anterior, la 85, Sto. Tomás dedica ocho artículos a discutir "el modo y orden del entendimiento", y sienta las bases de lo que acabamos de citar. El Art. 5 es especialmente importante para los propósitos de este trabajo. En él, el Aquinatense se pregunta si nuestro entendimiento entiende por composición y división, y responde diciendo que:

El entendimiento humano, por necesidad entiende por composición y división... el entendimiento humano no adquiere un conocimiento perfecto de las cosas en la primera aprehensión, sino que primero aprehende algo de la cosa... y luego entiende sus propiedades, sus accidentes, y las diversas relaciones de su esencia. Para esto, necesariamente va comparando una cosa con otra por composición o división, y de una composición y división procede a otra, lo que es precisamente el razonar...

...Pero el entendimiento angélico y el Divino -añade Sto. Tomás para que no quede duda alguna-, como todos los seres incorruptibles, tienen su perfección de una sola vez, desde el principio. Por consiguiente el entendimiento angélico y el Divino tienen el conocimiento completo de una cosa inmediata y perfectamente (Q.85, Art. 5).

En lo anterior se basa la arraigada convicción de los escolásti$\cos$, que hoy suena tan extraña, de que el individuo es incomunicable (individuum est ineffabile vel incomunicabile), "por cuanto lo que se dice de él es algo universal (uno o varios predicados). A consecuencia de ello, varios autores han indicado que del individuo sólo puede tenerse un conocimiento 'intuitivo'. Otros han manifestado que lo único que puede hacerse con un individuo es 'mostrarlo' (Ferrater Mora, 1980, 2: 1668).

Heimsoeth hace ver que esto se debe a que "únicamente el concepto de individuo es un concepto real y plenamente "determinado', un concepto 'completo", y añade:

Los predicados de toda la infinita sucesión temporal en que el individuo imperecedero se desenvuelve eternamente... han de estar encerrados en el concepto individual, contraídos en un punto, por decirlo así... L'individualité enveloppe l'infini. El número de los atributos, de los predicados que están encerrados en cada concepto es actualmente infinito. Este concepto no pue- 
de agotarse nunca en una definición y exposición finitas. El concepto universal debe la posibilidad de ser abarcado y relativamente agotado sólo a su relativa vacuidad y abstracción. (1960: 263-264)

Precisamente por la riqueza infinita de la realidad, y lo limitado de nuestra capacidad cognoscitiva, el conocimiento humano tiene que ser analítico: tenemos que conocer aplicando a la complejidad inmensa de lo real, ciertas categorías que, en la forma más simple son unidimensionales y dicotómicas, y que podemos enriquecer combinándolas y afinándolas, para transformarlas en tipologías multidimensionales y de más de dos valores.

Esto nos resulta insatisfactorio y aspiramos a un conocimiento globalizador e inmediato, que es lo que pretende lograr la intuición. Pero lo que nos parece intuitivo en realidad es un conocimiento analítico fino, de una realidad a la que podemos aplicar un esquema complejo de categorías casi sin pensarlo, por la familiaridad que tenemos con ella.

\section{EL CONOCIMIENTO DE LO SINGULAR EN LA EPISTEMOLOGÍA ACTUAL}

Sir Ernest Gombrich, el gran historiador y crítico del arte, con su postura filosófica popperiana, nos muestra cómo la epistemología reciente reencuentra a la escolástica en este punto preciso. Comentando las reflexiones de G. Boas sobre el adagio escolástico ya citado, de que individuum est ineffabile, dice:

...El individuo está fuera del alcance del habla porque el lenguaje, al emplear universales, impone una red de conceptos generales al abundante y variado mundo de los particulares y, al hacerlo, lo falsifica... (1991:163).

Y continúa, citando a Boas:

...puesto que expresamos nuestros hallazgos con substantivos y adjetivos comunes, con preposiciones y verbos, o sea con universales, tenemos la opción de aplicar términos generales a cosas y acontecimientos particulares, o no decir nada... (en Gombrich, 1991: 163). 
En otros lugares, Gombrich precisa:

La multitud de las experiencias potenciales es infinita, mientras el lenguaje, por su naturaleza misma, no puede consistir más que en un número finito de palabras. Pronto se nos acabarían sus recursos si la mente no fuera capaz de crear categorías, de repartir este escurridizo mundo nuestro en paquetes apropiados a los que se pueden atribuir a voluntad etiquetas más o menos permanentes. La terminología tradicional llama a las más permanentes "universales"; a las móviles, "metáforas". (1991: 74-75).

El lenguaje es lo que impone categorías a nuestro flujo de experiencia, pero no podría funcionar como herramienta versátil de comunicación si los universales con los que opera no fuesen algo borrosos en los bordes, y bastante flexibles para servir como metáforas. (1991: 19).

Esta última idea es muy importante, tanto para los propósitos de este trabajo como, más generalmente, para captar mejor la naturaleza del conocimiento y la comunicación humanas, y abrir las puertas al pluralismo y la tolerancia.

En efecto: los universales construidos por el hombre no son ni plenamente logrados, acabados, perfectos, que capten exactamente la realidad que siempre los rebasa, ni tampoco totalmente inexactos, imperfectos o arbitrarios. Se asemejan a la realidad pero no la agotan. Nuestros conceptos tienen "fundamento en la realidad", pero diversos grados de elaboración. Representan y construyen. Figuran y desfiguran. Son, en mayor o menor grado, metáforas. A veces tan olvidadas que creemos que no lo son.

CONCLUSIÓN. DE REDES Y METÁFORAS. LA METÁFORA DE LAS REDES

Al emplear universales -necesariamente, según Aristóteles y Sto. Tomás- el lenguaje, nos dice Gombrich, "impone una red de conceptos generales al abundante mundo de los particulares" (1991: 163).

Nos encontramos aquí una de las metáforas más utilizadas para tratar de entender, precisamente, el entendimiento humano. 
En su excelente Introducción a la teoría de la ciencia, y precisamente al final del Libro Primero, dedicado a lo que podríamos llamar la investigación convencional (análisis del lenguaje, deducción, inducción en las ciencias de la naturaleza y las ciencias sociales) Helmuth Seiffert utiliza la metáfora al reflexionar sobre la insuficiencia radical de nuestros conceptos, por más que los afinemos, para captar las sutilezas del mundo, y sobre el error en que se incurre al negar la existencia de aquello que escape a ellos. Seiffert se pregunta "¿Cómo son de recias nuestras mallas?", y escribe, basándose, según nos dice, en Sir Arthur Eddington:

Un pescador tiene una red con un grueso de mallas de $5 \mathrm{~cm}$. A través de esa red pasarán, pues, todos los peces menores de $5 \mathrm{~cm}$. Por eso nuestro pescador podría opinar que no hay peces menores de $5 \mathrm{~cm}$. (1977: 214).

Seiffert considera que en las ciencias naturales sí es posible manejar conceptos suficientemente precisos para el conocimiento adecuado de la realidad, pero que en las ciencias sociales no lo es, por lo que concluye que "en las ciencias sociales no basta la aplicación de métodos meramente analíticos" (1977: 215). Todo el Libro Segundo de su obra se dedicará a lo que él llama, en la más pura tradición alemana, los "métodos de las ciencias del espíritu", tratando de la fenomenología, la hermenéutica y la dialéctica.

Las consideraciones hechas anteriormente, a partir de la filosofía escolástica y de Gombrich, me llevan a una conclusión diferente, ya esbozada: la de que tanto en las ciencias de la naturaleza como en las del hombre nuestros conceptos son insuficientes para agotar el mundo, pero también la de que no tenemos alternativa real, ya que el conocimiento intuitivo, eventualmente reservado a los espíritus puros, nos está vedado a los simples mortales. No hay cerebros de neurona ágil o dialéctica, en la terminología de Deaño.

Trataré de expresar esta misma idea con una extensión -que será al mismo tiempo una "reducción al absurdo"- de la metáfora de las redes. 
Supongamos que nuestro pescador, sospechando de la existencia de peces menores a los que sacaba con su red de mallas de cinco centímetros, y deseando una pesca más abundante, decide fabricar una red de mallas menores, digamos de un centímetro. Obviamente atrapará más peces, pequeños crustáceos, algas tal vez, pero seguirán escapando peces y organismos menores.

La lógica de construcción de redes con mallas cada vez más finas puede seguirse sin dificultad, y cada vez se obtendrá una pesca mayor. Pero la consecuencia inevitable de tal esfuerzo es que cada vez resultará más dificultoso pescar con redes cada vez más finas.

En el extremo, una red de mallas infinitamente finas, que sería una no-red, una tela impermeable, tendría la propiedad teórica de sacar todo el contenido del mar de la realidad, pero ningún pescador, o por lo menos ninguno humano, podría sacarla. En el caso límite la barca de la que se tirara de la red impermeable naufragaría, agobiada por el peso infinito del agua del océano.

Me parece que los esfuerzos de numerosos investigadores de las ciencias del hombre por encontrar acercamientos más finos a las complejas realidades humanas se justifican plenamente, ante las innegables limitaciones, a veces tan burdas, de los acercamientos llamados convencionales, superficialmente etiquetados como cuantitativos.

Pero me parece también que esos esfuerzos frecuentemente pecan de ingenuidad al aspirar a un acercamiento auténticamente totalizador, realmente intuitivo.

Creo que tanto los escolásticos como los actuales popperianos tienen razón en creer que la intuición nos está vedada a los mortales.

Lo que no nos está vedado, en modo alguno, es el interminable proceso de perfeccionar nuestras redes mentales, de superar las dicotomías simples que irritaban a Gould, y substituirlas por entramados conceptuales complejos, por tipologías multidimensionales, que den cuenta de la realidad cada vez con mayor justeza, aunque nunca lleguen a agotarla. 
Según la versión más reciente que he encontrado de la metáfora, en la introducción que hace un destacado investigador norteamericano a un libro en el que presenta diferentes acercamientos metodológicos al tema de la evaluación educativa:

Tratar de pescar truchas en una corriente, usando un anzuelo diseñado para pescar salmones, y concluir de nuestros frustrados esfuerzos que no hay truchas, es sacar una conclusión probablemente equivocada. Nuestras redes definen lo que podemos atrapar. Si hay un mensaje que quisiera transmitir mediante este libro es el que lo deseable es que sepamos tejer muchos tipos de redes. (1985: 7)

La red perfecta es un ideal vedado al hombre. La pesca cognoscitiva de los humanos tiene que hacerse con redes imperfectas, "por composición y división", analíticamente.

Tal vez algunos lamenten lo anterior. Es posible también regocijarse, porque esta radical incapacidad humana es el fundamento del pluralismo y la tolerancia, ya que nadie puede pretender poseer la verdad íntegramente.

Y la semejanza relativa de nuestras redes conceptuales permite, al mismo tiempo, el respeto al misterio del otro, y su comprensión parcial. "Nunca he tenido mucha paciencia -dice Gombrich- con la afirmación de que el reto -de comprender un elemento de una tradición cultural ajena a la propia- es insuperable, y que estamos encerrados para siempre en nuestra lengua y perspectiva propias. Esta afirmación descansa en la suposición falsa de que entender es cuestión de todo o nada" (1991: 21).

\section{BIBLIOGRAFÍA}

DEAÑO, A., Introducción a la lógica formal, Madrid, Alianza, 1975.

EISNER, E., The Art of Educational Evaluation, Philadelphia, Falmer Press, 1985 (citado por GRADY B. E. y R. L. SANDERS, The evidence for Quality, San Francisco, Jossey Bass, 1992). 
FERRATER, MORA J., Diccionario de Filosofía, Madrid, Alianza, 1980, 4 vols.

GOMBRICH, E. H., Tributos. Versión cultural de nuestras tradiciones, México, Fondo de Cultura Económica, 1991 ( $1^{\text {a }}$ ed. en inglés 1984).

GOULD, S. J., Time's Arrow, Time's Cycle. Myth and Metaphor in the Discovery of Geological Time, Cambridge, Mass., Harvard University Press, 1987.

HEIMSOETH, H., Los seis grandes temas de la metafísica occidental, Madrid, Revista de Occidente, 1960 ( $1^{\mathrm{a}}$ ed. alemana 1922).

JACOB, J. C., "Theories of social and educational inequality: from dichotomy to typology", British Journal of Sociology of Education, Vol. 2 (1981), Nº 1, pp. 71-89.

LEFEBVRE, H., Lógica formal, lógica dialéctica, México, Siglo XXI, 1976 (ed. original francesa 1946).

MARTINEZ RIZO, F., "The Controversy About Quantification in Social Research: An Extension of Gage's 'Historical' Sketch", Educational Researcher, Vol. 20 (dec. 1991), No 9, pp. 9-12.

NOVACK, G., Introducción a la lógica. Lógica formal y lógica dialéctica, Barcelona, Fontamara, 1979 (trad. de la ed. americana de 1978; $1^{\text {a }}$ ed. 1942).

SEIFFERT, H., Introducción a la teoría de la ciencia, Barcelona, Herder, 1977 (1 $1^{a}$ ed. alemana 1969-1971). 
